\title{
Effect of Fullerene Derivates on Thermal and Crystallization Behavior of PBT/Decylamine- $\mathrm{C}_{60}$ and PBT/TCNEO- C $_{60}$ Nanocomposites
}

\author{
A. Woźniak-Braszak, ${ }^{1}$ K. Jurga, ${ }^{1,2}$ J. Jurga, ${ }^{2}$ M. Baranowski, ${ }^{1,2}$ \\ W. Grzesiak, ${ }^{3}$ B. Brycki, ${ }^{3}$ and K. Hołderna-Natkaniec ${ }^{1}$ \\ ${ }^{1}$ High Pressure Physics Division, Department of Physics, Adam Mickiewicz University, Umultowska 85, 61-614 Poznan, Poland \\ ${ }^{2}$ Laboratory of EPR Tomography, Institute of Materials Technology, Faculty of Mechanical Engineering and Management, \\ Poznan University of Technology, Piotrowo 3A, 60-965 Poznan, Poland \\ ${ }^{3}$ Laboratory of Microbiocides Chemistry, Faculty of Chemistry, Adam Mickiewicz University, Grunwaldzka 6, 60-780 Poznan, Poland
}

Correspondence should be addressed to A. Woźniak-Braszak, abraszak@amu.edu.pl

Received 26 January 2012; Revised 30 March 2012; Accepted 6 April 2012

Academic Editor: Sevan P. Davtyan

Copyright (C) 2012 A. Woźniak-Braszak et al. This is an open access article distributed under the Creative Commons Attribution License, which permits unrestricted use, distribution, and reproduction in any medium, provided the original work is properly cited.

The paper describes the process of the preparation of new nanocomposites based on poly(butylene terephthalate) and $\mathrm{C}_{60}$ nanoparticles modified by decylamine (DA) and tetracyanoethylene oxide (TCNEO), respectively. Thermal and crystallization properties of new synthesized nanocomposites were investigated by means of thermal differential scanning calorimetry (DSC). The experimental results demonstrate the effect of fullerene derivates, DA- $\mathrm{C}_{60}$ and TCNEO- $\mathrm{C}_{60}$, on the melting and crystallinity processes of nanocomposites. The morphology of new nanocomposites was investigated by SEM.

\section{Introduction}

Recently, nanocomposites have received great attention because of their improved physical properties compared to pure polymers or conventional microcomposites [1]. The addition of a nanometer scale filler may significantly improve the selected properties of the related polymer, namely mechanical, thermal, and barrier properties. It also provides a flame retardant character of polymers [2].

Poly(butylene terephthalate) (PBT) is the semicrystalline engineering thermoplastic with good mechanical properties, good mouldability (low melting temperature $T_{m}$ equal to about $496 \mathrm{~K}$ ), and a fast crystallization rate [3]. The repeating units of poly(butylene terephthalate) (PBT) have flexible segment built from four methylene groups as well as a hard segment of a terephthalate group [4]. PBT has two crystalline modifications, the $\alpha$ and $\beta$ forms, which both crystallize in a triclinic unit cell [5] and differ in the conformation of the central tetramethylene group. The $\alpha$ form exists in a relaxed state, whereas the $\beta$ form is observed only under special processing conditions that imply the application of stress to unoriented molecular chains $[6,7]$. The transition between the $\alpha$ form and $\beta$ form is reversible and takes place by stretching and through relaxation. Moreover, in poly(butylene terephthalate) different types of spherulites were formed upon crystallization from the melt, in the same crystalline structure $(\alpha)$, depending on the crystallization conditions $[7,8]$. PBT is often used as a matrix in nanocomposites because of its excellent moulding processing. The combination of outstanding electronic, conducting, and magnetic properties of fullerene $\mathrm{C}_{60}$ with the good processability of PBT seems to be promising for making improved polymeric material with novel physical and chemical properties. Due to the tendency of fullerene $\mathrm{C}_{60}$ towards agglomeration, the fullerene derivates, decylamine- $\mathrm{C}_{60}$ (DA$\mathrm{C}_{60}$ ) and tetracyanoethylene oxide- $\mathrm{C}_{60}\left(\right.$ TCNEO- $\left.\mathrm{C}_{60}\right)$, were synthesized. Then, new nanocomposites were obtained by direct reaction of PBT with fullerene adduct.

In this paper, the influence of different concentrations of fullerene derivates on thermal properties of nanocomposites was investigated by the DSC method and it was compared with that of the virgin PBT data. The comparative studies of 
morphology of surfaces of the virgin PBT and of nanocomposites were carried out using scanning electron microscopy (SEM).

\section{Experimental}

2.1. Materials. Commercial grade PBT was supplied by Aldrich Company. The fullerene derivates, $n$-decylamine- $\mathrm{C}_{60}$ $\left(\mathrm{DA}-\mathrm{C}_{60}\right)$ and tetracyanoethylene oxide- $\mathrm{C}_{60}\left(\mathrm{TCNEO}-\mathrm{C}_{60}\right)$, were prepared by the addition of $n$-decylamine and tetracyanoethylene oxide to fullerene $\mathrm{C}_{60}$ (Aldrich), respectively.

To obtain n-decylamine-fullerene $\left(\mathrm{DA}-\mathrm{C}_{60}\right), 154 \mathrm{mg}$ $(0,214 \mathrm{mmol})$ fullerene $\mathrm{C}_{60}$ with $119 \mathrm{mg}(0,642 \mathrm{mmol}) \mathrm{n}$ decylamine was stirred at $303 \mathrm{~K}$ for 20 hours under argon. The crude product was precipitated by addition of $20 \mathrm{~mL}$ methanol to the reaction mixture and filtered off. The product was purified by extraction with chloroform $(3 \times 30 \mathrm{~mL})$ to give, after evaporation of solvent, $229 \mathrm{mg}$ (84\%) of $n$ decylamine-fullerene. The elemental analysis has confirmed monosubstitution of $n$-decylamine to fullerene $\mathrm{C}_{60}$.

Tetracyanoethylene oxide- $\mathrm{C}_{60}\left(\right.$ TCNEO- $\left.\mathrm{C}_{60}\right)$ adduct was obtained in the reaction of $200 \mathrm{mg}(0.278 \mathrm{mmol})$ fullerene $\mathrm{C}_{60}$ and $40 \mathrm{mg}(0.278 \mathrm{mmol})$ tetracyanoethylene oxide in toluene $(150 \mathrm{~mL})$. The reaction mixture was refluxed for 15 hours under argon. After evaporation of solvent, the brown solid residue was dissolved in chloroform and passed through Cellit. The eluate was evaporated under reduced pressure to give the solid product, which was dried in the vacuum desiccator $(0.05 \mathrm{mmHg})$ at $298 \mathrm{~K}$ for 24 hours. The yield was $124 \mathrm{mg}$ (52\%). The purity of tetracyanoethylene oxide- $\mathrm{C}_{60}$ (TCNEO- $\mathrm{C}_{60}$ ) adduct was confirmed by elemental analysis, FTIR, and MS spectra.

Fullerenation of PBT by direct reaction between DA$\mathrm{C}_{60}$ and TCNEO- $\mathrm{C}_{60}$ was carried out according to the Olah method, using $\mathrm{AlCl}_{3}$ as a catalyst [9]. To prepare $\mathrm{PBT} / n$ decylamine-fullerene (PBT/DA- $\mathrm{C}_{60}, 0,2 \%$ wt. of fullerene adduct), $5.0 \mathrm{~g}$ PBT was dissolved in 43,3 $\mathrm{g} \mathrm{1,1,1,3,3,3-}$ hexafluor-2-propanol and then 129,9 g chloroform, 50,0 mg anhydrous aluminum chloride, and $10,0 \mathrm{mg} n$-decylaminefullerene $\left(\mathrm{DA}-\mathrm{C}_{60}\right)$ were added. The reaction mixture was refluxed for 10 hours under argon. The product was precipitated by addition of $500 \mathrm{~g}$ cold water to the chilled reaction mixture. The PBT/DA- $\mathrm{C}_{60} \quad 0,2 \%$ wt. of fullerene adduct $(500: 1)$ was filtered off and dried in the vacuum desiccator $(0.05 \mathrm{mmHg})$ at $298 \mathrm{~K}$ for 24 hours. The PBT/TCNEO-C 60 $0,2 \%$ wt. of fullerene adduct was obtained in the same way using TCNEO- $\mathrm{C}_{60}$ instead of DA- $\mathrm{C}_{60}$. The other samples of PBT with fullerene adducts with different proportions, that is, $1000: 1$ (0.1\% wt. of fullerene adduct) and 10000:1 $(0.01 \%$ wt. of fullerene adduct), were prepared similarly, using 5.0 and $0.5 \mathrm{mg}$ fullerene derivatives, respectively.

2.2. Differential Scanning Calorimetry (DSC). The crystallization and melting studies of the virgin PBT and of the nanocomposites with different contents of fullerene derivates were carried out on a differential scanning calorimeter DSC Q2000 TA Instruments. Aluminium sample pans were used with sample weights in the region of 5 to $10 \mathrm{mg}$. The thermal

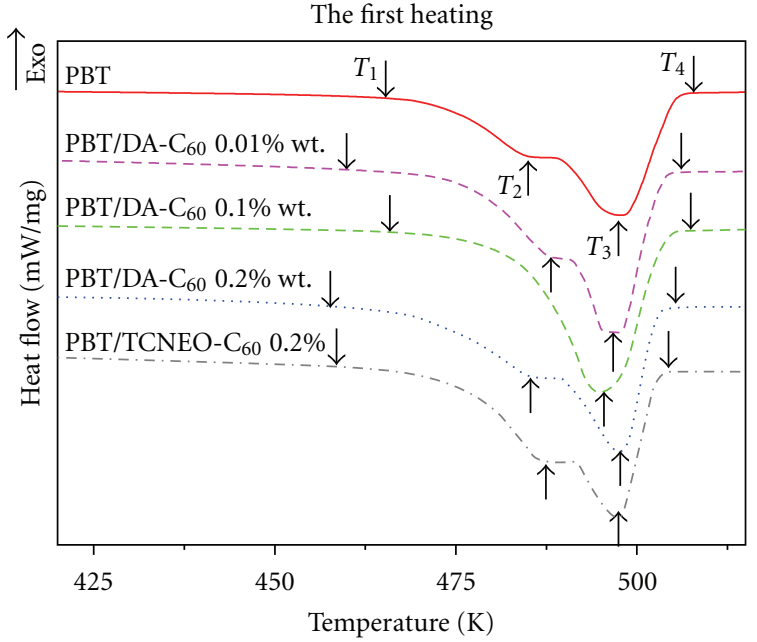

FIGURE 1: The DSC first heating curves of the virgin PBT, PBT/DA$\mathrm{C}_{60}$, and PBT/TCNEO- $\mathrm{C}_{60}$ nanocomposites with different contents of $\mathrm{DA}-\mathrm{C}_{60}$ and $\mathrm{TCNEO}-\mathrm{C}_{60}$ fullerene derivates, respectively.

parameters were obtained from the DSC thermograms of the sample heated up to $550 \mathrm{~K}$ and cooled down to $223 \mathrm{~K}$ and then reheated and recooled to the same temperatures as during the first cycle. All operations were performed at a rate of $10 \mathrm{~K} / \mathrm{min}$ in a nitrogen atmosphere, using an empty aluminium sample pan as the reference. The first heating eliminated the influence of thermal history. The melting parameters from the reheating scans represent morphologies of samples crystallized from the melt under identical cooling conditions. The heat of crystallization was determined from the cooling scans. Glass transition temperatures $\left(T_{g}\right)$ were estimated at the midpoint of the specific heat steps, while melting temperatures $\left(T_{m}\right)$ and crystallisation temperatures $\left(T_{c}\right)$ were measured at the maxima of the thermogram peaks. The melting enthalpies $\Delta H_{m}$ and the crystallization enthalpies $\Delta H_{c}$ were obtained from the areas of melting peaks and crystallization peaks, respectively.

2.3. SEM Study. The morphology of the PBT and nanocomposites was examined by scanning electron microscopy (SEM) using a Zeiss EVO-25 LS Scanning Electron Microscope operating with an acceleration voltage of $20 \mathrm{kV}$. The powder samples of PBT and the nanocomposites were dusted on the double-side conductive carbon films and then were coated with a thin gold layer in the order of nm by Balzers sputter coater SCD 050 in the atmosphere of argon.

\section{DSC Results}

3.1. Melting Behavior of the Virgin PBT and the Nanocomposites. Figure 1 shows DSC heating curves of the virgin PBT, PBT/DA-C 60 , and PBT/TCNEO- $\mathrm{C}_{60}$ nanocomposites with different contents of $\mathrm{DA}-\mathrm{C}_{60}$ and $\mathrm{TCNEO}-\mathrm{C}_{60}$ fullerene derivates, respectively.

The melting parameters including the onset of melting $\left(T_{1}\right)$, melting peak temperatures $\left(T_{2}, T_{3}\right)$, completion of 
TABLE 1: DSC parameters obtained during the first heating for PBT, PBT/DA- $\mathrm{C}_{60}$, and PBT/TCNEO- $\mathrm{C}_{60}$ nanocomposites, respectively.

\begin{tabular}{|c|c|c|c|c|c|c|c|c|}
\hline $\begin{array}{l}\text { Material with weight } \\
\text { contents of fullerene derivate }\end{array}$ & $T_{g}[\mathrm{~K}]$ & $\begin{array}{c}\text { Onset of } \\
\text { melting } \\
T_{1}[\mathrm{~K}]\end{array}$ & $\begin{array}{c}\text { Melting } \\
\text { peak first } \\
T_{2}[\mathrm{~K}]\end{array}$ & $\begin{array}{c}\text { Melting } \\
\text { peak second } \\
T_{3}[\mathrm{~K}]\end{array}$ & $\begin{array}{c}\text { Completion of } \\
\text { melting } \\
T_{4}[\mathrm{~K}]\end{array}$ & $\begin{array}{c}\text { Peak width } \\
T_{4}-T_{1}[\mathrm{~K}]\end{array}$ & $\begin{array}{l}\text { The melting } \\
\text { enthalpy } \\
\Delta H_{m}[\mathrm{~J} / \mathrm{g}]\end{array}$ & $\begin{array}{l}\text { The estimated } \\
\text { value of the } \\
\text { crystallinity } \\
\chi_{c}[\%]\end{array}$ \\
\hline Virgin PBT & 328 & 465 & 485 & 498 & 508 & 43 & 72 & 51 \\
\hline PBT/DA-C ${ }_{60} 0.01 \%$ wt. & 331 & 459 & 489 & 497 & 506 & 47 & 75 & 53 \\
\hline PBT/DA-C $600.1 \%$ wt. & 335 & 465 & & 495 & 508 & 43 & 74 & 52 \\
\hline PBT/DA-C $600.2 \%$ wt. & 333 & 457 & 487 & 498 & 505 & 48 & 75 & 53 \\
\hline PBT/TCNEO-C $600.2 \%$ wt. & 333 & 457 & 488 & 497 & 504 & 48 & 75 & 53 \\
\hline
\end{tabular}

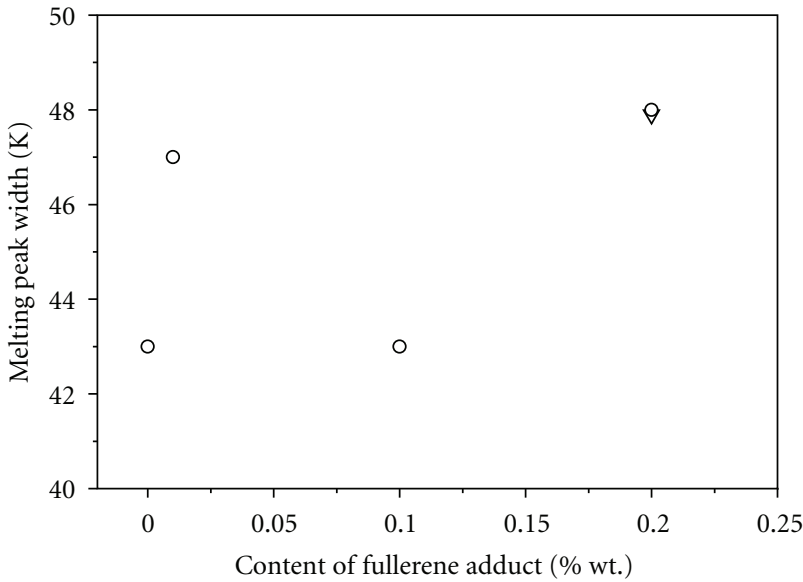

Figure 2: The effect of the increasing of the peak width as a function of content fullerene derivates during the first heating for $\mathrm{PBT} / \mathrm{DA} / \mathrm{C}_{60}$ nanocomposites (circles) and for $\mathrm{PBT} / \mathrm{TCNEO} / \mathrm{C}_{60}$ nanocomposites (triangle).

melting $\left(T_{4}\right)$, the melting temperature range $\left(T_{4}-T_{1}\right)$, the width of the melting peak, the melting enthalpy $\Delta H_{m}$ and the degree of crystallinity $\left(\chi_{c}\right)$ were estimated from the first heating scans and collected in Table 1. All DSC curves show double overlapping melting peaks, which were explained based on the simultaneous melting and recrystallization of a distribution of crystallites of various sizes and different degrees of order [10].

Controversy arises over the origin of the double melting behaviour of PBT. Initially, it was explained by the melting of crystals possessing differing morphologies or the melting of distributions of a single morphological form with a different size and perfection [11]. Then, the double melting behaviour of PBT was explained by the melt-recrystallization process $[12,13]$. In this model the low-temperature endothermic peak was caused by the melting of original crystals formed during cooling, which have a low degree of perfection and wide distribution of crystals. The sharp high temperature peak was explained by the melting of reorganized more perfect crystals during a heating scan. It was attributed to a narrow distribution in thickness of lamellar crystallite.

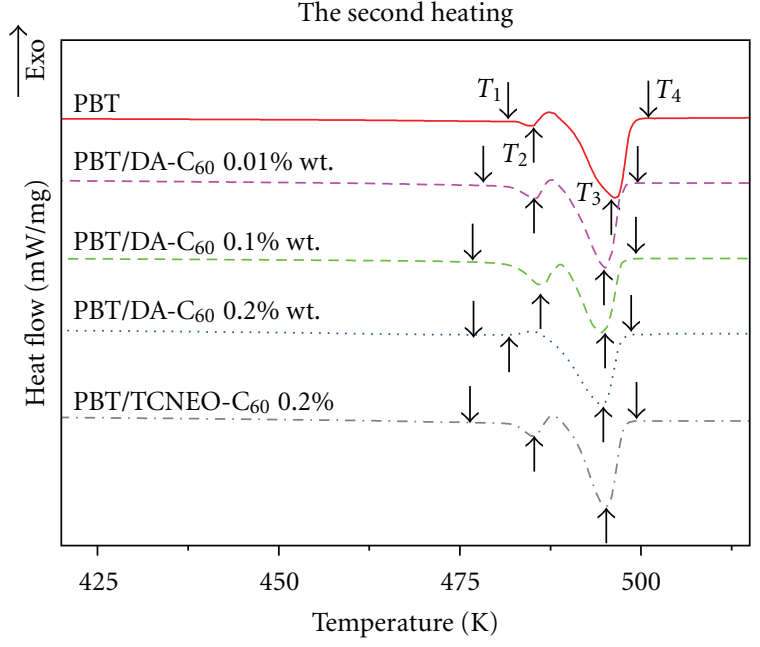

FIGURE 3: The DSC second heating curves of virgin PBT, PBT/DA$\mathrm{C}_{60}$, and PBT/TCNEO- $\mathrm{C}_{60}$ nanocomposites with different contents of fullerene derivates, respectively.

The degrees of crystallinity of the virgin PBT, PBT/DA$\mathrm{C}_{60}$, and PBT/TCNEO- $\mathrm{C}_{60}$ nanocomposites were calculated according to the formula

$$
\chi_{c}=\frac{\Delta H_{m}}{\Delta H_{f}} 100 \%,
$$

as the ratio between the area of the endothermic peak (melting enthalpy $\Delta H_{m}$ ) and the theoretical value of enthalpy of homopolymer for $100 \%$ crystalline poly (butylene terephthalate) $\Delta H_{f}=142 \mathrm{~J} / \mathrm{g}[14,15]$. The estimated values of crystallinity $\chi_{c}$ presented in Table 1 slightly increase for nanocomposites in comparison with those for the virgin PBT.

The melting range, which is the difference between the completion and the onset of melting $\left(T_{4}-T_{1}\right)$, is wider in the nanocomposites as compared to that in the virgin $\mathrm{PBT}$ except for $\mathrm{PBT} / \mathrm{DA}-\mathrm{C}_{60}$ of $0.1 \%$ wt. of fullerene adduct, which is illustrated in Figure 2. These differences suggest that nanocomposites possess a wider distribution of crystal size than the virgin PBT. The temperature of the first melting peak was shifted towards higher temperatures for 
TABLE 2: DSC parameters obtained during the first cooling for PBT, PBT/DA- $\mathrm{C}_{60}$, and PBT/TCNEO- $\mathrm{C}_{60}$ nanocomposites, respectively.

\begin{tabular}{|c|c|c|c|c|c|c|c|}
\hline $\begin{array}{l}\text { Material with weight } \\
\text { contents of fullerene } \\
\text { derivate }\end{array}$ & $\begin{array}{c}\text { Onset of } \\
\text { crystallization } \\
T_{5}[\mathrm{~K}] \\
\end{array}$ & $\begin{array}{c}\text { Peak } \\
\text { crystallization } \\
T_{6}[\mathrm{~K}] \\
\end{array}$ & $\begin{array}{c}\text { Completion of } \\
\text { crystallization } \\
T_{7}[\mathrm{~K}]\end{array}$ & $\begin{array}{c}\text { Peak width } \\
T_{7}-T_{5}[\mathrm{~K}]\end{array}$ & $\begin{array}{c}\text { Degree of } \\
\text { supercooling } \\
T_{3}-T_{5}[\mathrm{~K}]\end{array}$ & $\begin{array}{c}\text { The crystallization } \\
\text { enthalpy } \\
\Delta H_{c}[\mathrm{~J} / \mathrm{g}]\end{array}$ & $\Delta H_{c} / t[\mathrm{~J} / \mathrm{gs}]$ \\
\hline Virgin PBT & 475 & 468 & 461 & 14 & 23 & 60 & 0.71 \\
\hline PBT/DA-C $600.01 \%$ wt. & 476 & 469 & 462 & 14 & 21 & 64 & 0.76 \\
\hline PBT/DA-C 60 0.1\% wt. & 478 & 474 & 464 & 14 & 17 & 64 & 0,76 \\
\hline PBT/DA-C ${ }_{60} 0.2 \%$ wt. & 473 & 464 & 451 & 22 & 25 & 63 & 0,75 \\
\hline PBT/TCNEO-C ${ }_{60} 0.2 \%$ wt. & 475 & 468 & 461 & 14 & 22 & 66 & 0,79 \\
\hline
\end{tabular}

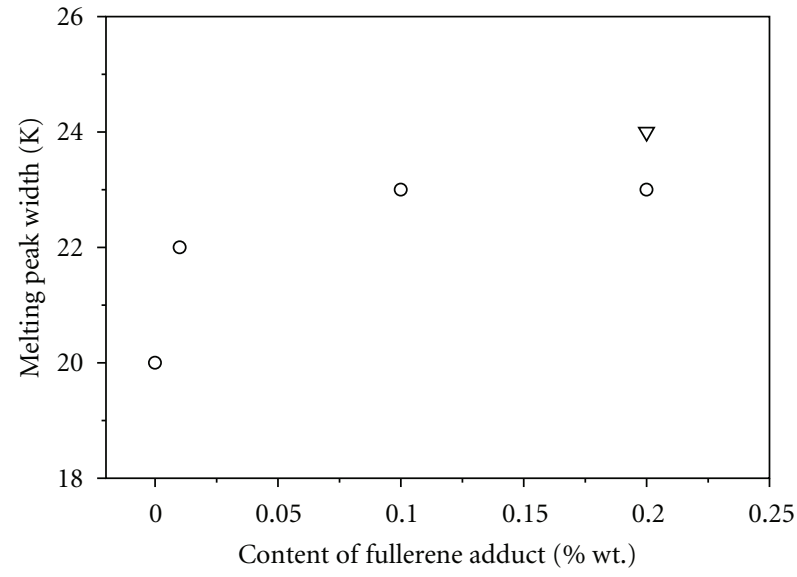

FIGURE 4: The effect of increasing peak width as a function of content fullerene derivates during the second heating for PBT/DA$\mathrm{C}_{60}$ nanocomposites (circles) and for PBT/TCNEO- $\mathrm{C}_{60}$ nanocomposites (triangle).

all nanocomposites, whereas the temperature of the second melting peak was insignificantly shifted to lower temperatures.

Figure 3 presents the DSC reheating curves of virgin PBT, $\mathrm{PBT} / \mathrm{DA}-\mathrm{C}_{60}$, and of PBT/TCNEO- $\mathrm{C}_{60}$ nanocomposites with different contents of fullerene derivates, respectively. It was evident that DCS reheating thermograms of all samples show two distinct endothermic melting peaks. The small exothermic peaks between the double melting endothermic peaks in all DSC curves for PBT/TCNEO- $\mathrm{C}_{60}$ and for PBT/DA$\mathrm{C}_{60}$ nanocomposites and for the virgin $\mathrm{PBT}$ confirm the hypothesis that melting of $\mathrm{PBT}$ proceeds through the process of melting of original crystals, recrystallization, and the melting of recrystallized crystals.

The low-temperature peak was wide and has a small amplitude. It was connected with the melting of small crystallites, which have a wide size of distribution. The other melting peak in the higher temperature side was narrow and has a bigger amplitude. It means that large-size crystallites with narrower distribution melt in this temperature range [12]. Both the onset and the completion of melting for nanocomposites occurred in lower temperatures than those of the virgin PBT. The melting peak width $\left(T_{4}-T_{1}\right)$ for nanocomposites presented in Figure 4 was bigger in comparison with that of the virgin PBT. It may indicate

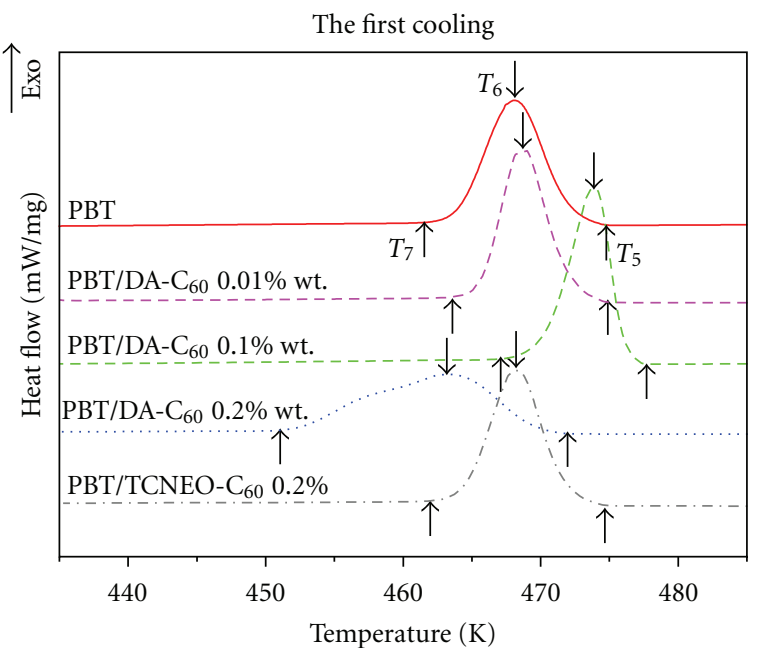

FIGURE 5: The DSC first cooling curves of virgin PBT, PBT/DA- $\mathrm{C}_{60}$, and $\mathrm{PBT} / \mathrm{TCNEO}-\mathrm{C}_{60}$ nanocomposites with different contents of fullerene derivates, respectively.

that, likewise during the first heating, the nanocomposites have less perfect crystallites with a broader distribution of crystallites size compared to those of the virgin PBT. The data on the melting behaviour for all the samples determined from the second heating are summarized in Table 3. The melting temperatures with the exception of the temperature of the melting of the first peak of PBT/DA-C 60 of $0.2 \%$ wt. of fullerene adduct were kept about the same as those of the virgin PBT.

The enthalpies of melting and recrystallization were calculated from the area under peaks. The degrees of crystallinity were estimated using the equation

$$
\chi_{c}=\frac{\Delta H_{m 1}+\Delta H_{m 2}-\Delta H_{\mathrm{rec}}}{\Delta H_{f}}=\frac{\Delta H_{m}}{\Delta H_{f}} \cdot 100 \%,
$$

where $\Delta H_{m 1}$ is the melting enthalpy obtained from the first endothermic peak, $\Delta H_{m 2}$ is the melting enthalpy obtained from the second endothermic peak, $\Delta H_{\text {rec }}$ is the enthalpy of recrystallization, and $\Delta H_{f}=142 \mathrm{~J} / \mathrm{g}$. The increase in the degree of crystallinity by $6 \%$ for PBT/DA- $\mathrm{C}_{60}$ of $0.01 \%$ wt. to $22 \%$ for $\mathrm{PBT} / \mathrm{DA}-\mathrm{C}_{60}$ of $0.1 \%$ of fullerene adduct in comparison with that for the virgin PBT could be explained on the basis of the heterogeneous nucleation provided by fullerene derivates in PBT [16]. 
TABLE 3: DSC parameters obtained during the second heating for PBT, PBT/DA- $\mathrm{C}_{60}$, and PBT/TCNEO-C 60 nanocomposites, respectively.

\begin{tabular}{|c|c|c|c|c|c|c|c|}
\hline $\begin{array}{l}\text { Material with weight } \\
\text { contents of fullerene } \\
\text { derivate }\end{array}$ & $\begin{array}{c}\text { Onset of } \\
\text { melting } \\
T_{1}[\mathrm{~K}]\end{array}$ & $\begin{array}{c}\text { Melting peak } \\
\text { first } \\
T_{2}[\mathrm{~K}] \\
\end{array}$ & $\begin{array}{c}\text { Melting peak } \\
\text { second } \\
T_{3}[\mathrm{~K}]\end{array}$ & $\begin{array}{c}\text { Completion } \\
\text { of melting } \\
T_{4}[\mathrm{~K}]\end{array}$ & $\begin{array}{c}\text { Peak width } \\
T_{4}-T_{1}[\mathrm{~K}]\end{array}$ & $\begin{array}{c}\text { The melting } \\
\text { enthalpy } \\
\Delta H_{m}[\mathrm{~J} / \mathrm{g}]\end{array}$ & $\begin{array}{c}\text { The estimated value } \\
\text { of the crystallinity } \\
\chi_{c}[\%]\end{array}$ \\
\hline Virgin PBT & 481 & 485 & 496 & 501 & 20 & 46 & 32 \\
\hline PBT/DA-C $600.01 \%$ wt. & 478 & 485 & 495 & 500 & 22 & 48 & 34 \\
\hline PBT/DA-C 60 0.1\% wt. & 476 & 486 & 495 & 499 & 23 & 55 & 39 \\
\hline $\mathrm{PBT} / \mathrm{DA}-\mathrm{C}_{60} 0.2 \% \mathrm{wt}$. & 476 & 480 & 495 & 499 & 23 & 50 & 35 \\
\hline PBT/TCNEO-C ${ }_{60} 0.2 \%$ wt. & 475 & 485 & 495 & 499 & 24 & 51 & 36 \\
\hline
\end{tabular}

TABLE 4: DSC parameters obtained during the second cooling for PBT, PBT/DA- $\mathrm{C}_{60}$, and PBT/TCNEO-C 60 nanocomposites, respectively.

\begin{tabular}{|c|c|c|c|c|c|c|c|}
\hline $\begin{array}{l}\text { Material with weight } \\
\text { contents of fullerene } \\
\text { derivate }\end{array}$ & $\begin{array}{c}\text { Onset of } \\
\text { crystallization } \\
T_{5}[\mathrm{~K}]\end{array}$ & $\begin{array}{c}\text { Peak } \\
\text { crystallization } \\
T_{6}[\mathrm{~K}]\end{array}$ & $\begin{array}{c}\text { Completion of } \\
\text { crystallization } \\
T_{7}[\mathrm{~K}]\end{array}$ & $\begin{array}{c}\text { Peak width } \\
T_{7}-T_{5}[\mathrm{~K}]\end{array}$ & $\begin{array}{c}\text { Degree of } \\
\text { supercooling } \\
T_{3}-T_{5}[\mathrm{~K}]\end{array}$ & $\begin{array}{c}\text { The } \\
\text { crystallization } \\
\text { enthalpy } \\
\Delta H_{c}[\mathrm{~J} / \mathrm{g}]\end{array}$ & $\Delta H_{c} / t[\mathrm{~J} / \mathrm{gs}]$ \\
\hline Virgin PBT & 476 & 468 & 461 & 15 & 20 & 59 & 0,66 \\
\hline $\mathrm{PBT} / \mathrm{DA}-\mathrm{C}_{60} 0.01 \% \mathrm{wt}$. & 477 & 470 & 464 & 13 & 18 & 64 & 0,82 \\
\hline PBT/DA-C $600.1 \%$ wt. & 478 & 474 & 467 & 11 & 17 & 66 & 1 \\
\hline PBT/DA-C $600.2 \%$ wt. & 473 & 464 & 452 & 21 & 22 & 62 & 0,5 \\
\hline PBT/TCNEO-C $600.2 \%$ wt. & 477 & 472 & 466 & 11 & 18 & 63 & 0,95 \\
\hline
\end{tabular}

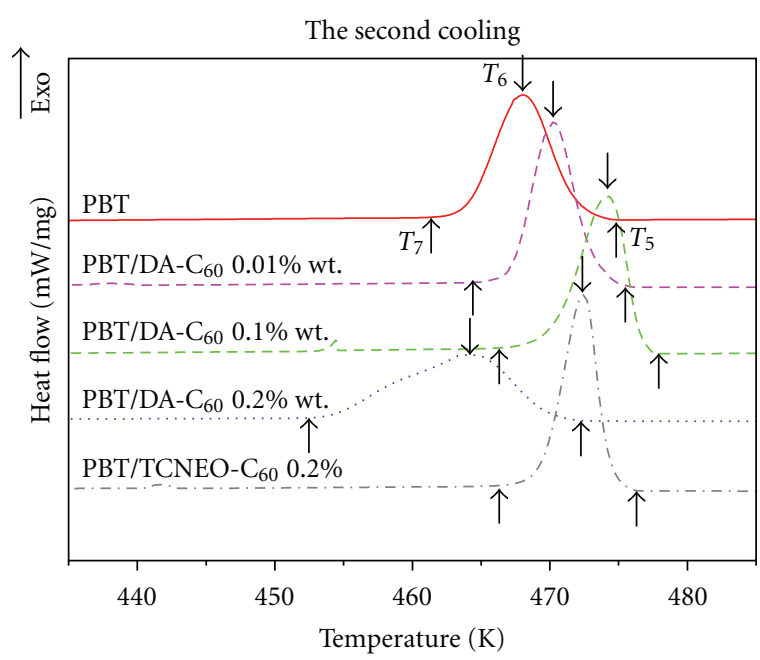

FIGURE 6: The DSC second cooling curves of virgin PBT, PBT/DA$\mathrm{C}_{60}$, and $\mathrm{PBT} / \mathrm{TCNEO}-\mathrm{C}_{60}$ nanocomposites with different contents of fullerene derivates, respectively.

3.2. Crystallization Behavior of the Virgin PBT and the Nanocomposites. Figures 5 and 6 present the DSC thermograms of the virgin $\mathrm{PBT}$ and nanocomposites with different contents of $\mathrm{DA}-\mathrm{C}_{60}$ and $\mathrm{TCNEO}-\mathrm{C}_{60}$ adducts obtained during the first and the second cooling. The parameters characterizing the crystallization behavior obtained during the first and the second cooling such as the onset, completion, peak width, and enthalpy of the crystallization were collected in Tables 2 and 4, respectively.

It was observed that the onset of crystallization $\left(T_{5}\right)$ of nanocomposites during the first and the second cooling was not altered significantly. The crystallization peak

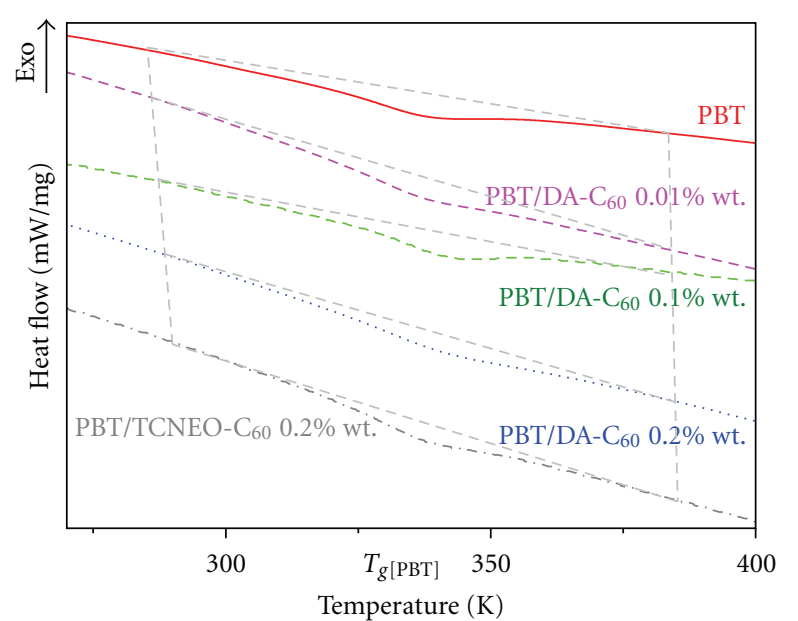

FIgure 7: The thermograms of the virgin PBT, PBT/DA- $\mathrm{C}_{60}$, and $\mathrm{PBT} / \mathrm{TCNEO}-\mathrm{C}_{60}$ nanocomposites with different contents of DA$\mathrm{C}_{60}$ and TCNEO- $\mathrm{C}_{60}$ fullerene derivates in the vicinity of the glass transition temperature, respectively.

temperature $\left(T_{6}\right)$ measured at maximum crystallization rate, especially during the second cooling, indicates a tendency towards an increase. It was shifted towards higher temperatures by about a few degrees in comparison with that of the virgin PBT, which points to the modification of the nucleation process [17] and suggesting the accelerated crystallization of PBT fullerene nanocomposites. Only the PBT/DA-C 60 sample of $0.2 \%$ wt. of fullerene adduct shows different behavior. Its characteristic crystallization temperatures were shifted to lower temperatures in comparison with those of the virgin PBT and other composites. Moreover, the peak of crystallization was very broad and has a lower 


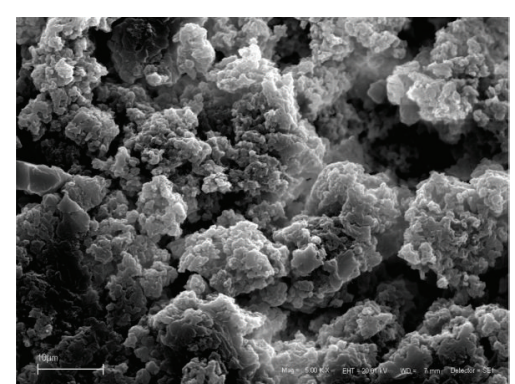

PBT $\mathrm{Mg}=5 \mathrm{kX}$

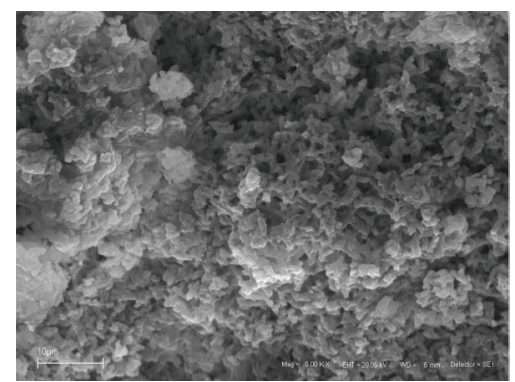

PBT/DA-C $600.01 \%$ wt. $\mathrm{Mg}=5 \mathrm{kX}$

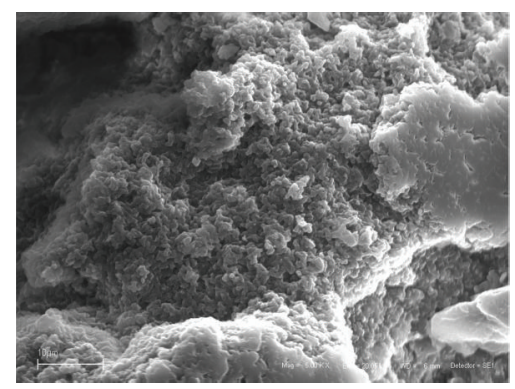

PBT/DA-C $60.2 \%$ wt. $\quad \mathrm{Mg}=5 \mathrm{kX}$

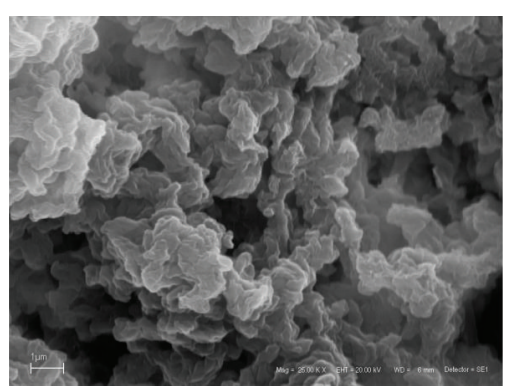

PBT $\mathrm{Mg}=25 \mathrm{kX}$

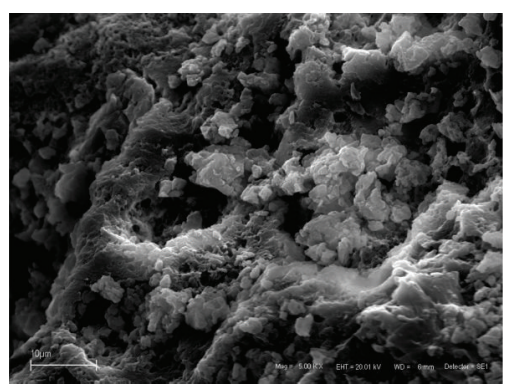

PBT/DA-C $600.1 \%$ wt. $\quad \mathrm{Mg}=5 \mathrm{kX}$

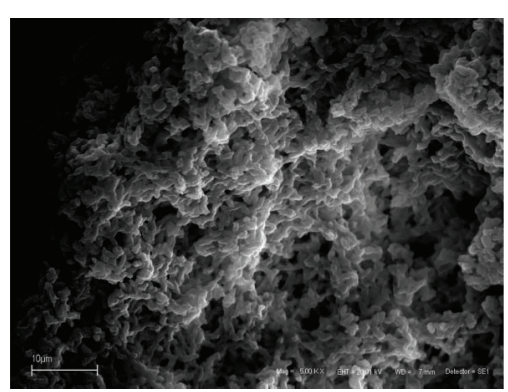

PBT/TCNEO-C $600.2 \%$ wt. $\mathrm{Mg}=5 \mathrm{kX}$

FIGURE 8: SEM micrographs of the virgin PBT, PBT/DA-C $60.01 \%, \mathrm{PBT} / \mathrm{DA}-\mathrm{C}_{60} 0.1 \%, \mathrm{PBT} / \mathrm{DA}-\mathrm{C}_{60} 0.2 \%$, and PBT/TCNEO-C $60.2 \%$ nanocomposites, respectively.

amplitude. The crystallization behaviour of PBT/DA-C 60 of $0.2 \%$ wt. of fullerene adduct is different from that of other studied samples, which may suggest that the process of crystallization is hindered for this nanocomposite. This sample will not be included in further considerations.

In general, during the second cooling, nanocomposites exhibit a narrower width of exothermic crystallization peaks $\left(T_{7}-T_{5}\right)$ by $2 \mathrm{~K}$ to $4 \mathrm{~K}$ than that of the virgin PBT with the exception of PBT/DA- $\mathrm{C}_{60}$ of $0.2 \%$ wt. of fullerene adduct. The heat of crystallization $\left(\Delta H_{c}\right)$ increases for nanocomposites.

The most important parameter describing the process of crystallization was the rate of crystallization. It is defined as the ratio of the heat of crystallization to the time, which is estimated between the onset and the completion of crystallization $\left(\Delta H_{c} / t\right)$. The crystallization rate for nanocomposites was greater than that of the virgin PBT as given in Tables 2 and 4 . The degree of supercooling $\left(T_{3}-T_{5}\right)$ could be a measurement of a polymer crystallizability, what means that if the degree of supercooling is lower then the crystallization rate is greater [18]. The degrees of supercooling $\left(T_{3}-T_{5}\right)$ collected in Tables 2 and 4 confirm that the overall crystallization rate for the nanocomposites is greater than that of the virgin $\mathrm{PBT}$.

The crystallization peak temperatures for all studied nanocomposites are higher than those of the virgin PBT; what is more is that nanocomposites are characterized by narrower crystallization peak width $\left(T_{7}-T_{5}\right)$, smaller degree of supercooling $\left(T_{3}-T_{5}\right)$, and greater crystallization rate $\left(\Delta H_{c} / t\right)$. These results indicate that the crystallization is accelerated in nanocomposites.

3.3. The Glass Transition Temperature. Glass transition temperatures were estimated as the half-step temperature related to the change of heat capacity, which appears during the transition between the glassy and rubbery states. Figure 7 collects the DSC thermograms of the studied samples in the vicinity of the glass transition temperature. The DSC results show increasing glass transition temperatures $T_{g}$ for nanocomposites with increasing weight of the fullerene filler. The biggest increase in $T_{g}$ by about $7 \mathrm{~K}$ was noticed for PBT/DA- $\mathrm{C}_{60}$ of $0.1 \% \mathrm{wt}$. of fullerene adduct. The observed 
increase of $T_{g}$ may have been due to interfacial interaction in nanocomposites between the polymer matrix and the fullerene derivates $[16,17,19,20]$.

3.4. SEM Study. The surface analysis of SEM micrographs of the virgin PBT, PBT/DA-C $600.01 \%$ wt., PBT/DA-C $600.1 \%$ wt., PBT/DA-C $600.2 \%$ wt., and PBT/TCNEO-C $600.2 \%$ wt. nanocomposites presented in Figure 8 indicates a variation of surface morphology as a function of contents of fullerene derivates adduct. The increasing of the concentration of DA- $\mathrm{C}_{60}$ adduct from $0.01 \%$ wt. to $0.2 \% \mathrm{wt}$. leads to lower roughness of the surface of nanocomposites in comparison with that of the virgin PBT. The observed structure of the virgin $\mathrm{PBT}$ is fine-grained in comparison with that of nanocomposites. For nanocomposite PBT/TCNEO- $\mathrm{C}_{60}$ $0.2 \%$ wt. a decrease in aggregates sizes was observed in comparison with those of PBT/DA- $\mathrm{C}_{60}$ nanocomposites, which could be explained by bigger chemical activity of TCNEO$\mathrm{C}_{60}$ fullerene derivates.

\section{Conclusion}

The results confirm that the thermal properties as well as molecular dynamics $[14,21]$ of $\mathrm{PBT} / \mathrm{DA}_{-} \mathrm{C}_{60}$ and $\mathrm{PBT} / \mathrm{TCNEO}-\mathrm{C}_{60}$ nanocomposites were changed in comparison with those of the virgin PBT. The studies of the melting and cooling processes show differences for the virgin $\mathrm{PBT}$ and $\mathrm{PBT} / \mathrm{DA}-\mathrm{C}_{60}$ and $\mathrm{PBT} / \mathrm{TCNEO}-\mathrm{C}_{60}$ nanocomposites. Fullerene derivates, DA- $\mathrm{C}_{60}$ and TCNEO- $\mathrm{C}_{60}$, affected the glass transition temperature, which indicates tendency towards shifting to higher temperatures.

Analysis of DSC curves and SEM micrographs shows that nanocomposites possess crystallites with a broader distribution of size and a greater degree of crystallinity. It was shown that melting temperatures are not altered by fullerene derivates. The nanocomposites with the exception of PBT/DA- $\mathrm{C}_{60}$ of $0.2 \% \mathrm{wt}$. of fullerene adduct exhibit the narrower crystallization peak width, greater crystallization rate, and smaller degree of supercooling. These results suggest that fullerene derivates can act as heterogeneous nucleating agents in the nucleation of PBT crystallization, accelerating the process of crystallization.

\section{Acknowledgment}

The present paper was supported by Grant no. 507080633 of Polish Ministry of Sciences and Education.

\section{References}

[1] E. Petrovicova, R. Knight, L. S. Schadler, and T. E. Twardowski, "Nylon 11/silica nanocomposite coatings applied by the HVOF process. I. Microstructure and morphology," Journal of Applied Polymer Science, vol. 77, no. 8, pp. 1684-1699, 2000.

[2] J. Xiao, Y. Hu, Z. Wang, Y. Tang, Z. Chen, and W. Fan, "Preparation and characterization of poly(butylene terephthalate) nanocomposites from thermally stable organic-modified montmorillonite," European Polymer Journal, vol. 41, no. 5, pp. 1030-1035, 2005.
[3] B. S. Hsiao, Z. G. Wang, F. Yeh, Y. Gao, and K. C. Sheth, "Time-resolved X-ray studies of structure development in poly(butylene terephthalate) during isothermal crystallization," Polymer, vol. 40, no. 12, pp. 3515-3523, 1999.

[4] K. Song, "Formation of polymorphic structure and its influences on properties in uniaxially stretched polybutylene terephthalate films," Journal of Applied Polymer Science, vol. 78, no. 2, pp. 412-423, 2000.

[5] C. M. Wu and C. W. Jiang, "Crystallization and morphology of polymerized cyclic butylene terephthalate," Journal of Polymer Science, Part B, vol. 48, no. 11, pp. 1124-1134, 2010.

[6] M. Yokouchi, Y. Sakakibara, Y. Chatani, H. Tadokoro, T. Tanaka, and K. Yoda, "Structures of two crystalline forms of poly(butylene terephthalate) and reversible transition between them by mechanical deformation," Macromolecules, vol. 9, no. 2, pp. 266-273, 1976.

[7] M. L. Di Lorenzo and M. C. Righetti, "Crystallization of poly(butylene terephthalate)," Polymer Engineering and Science, vol. 43, no. 12, pp. 1889-1894, 2003.

[8] R. S. Stein and A. Misra, "Morphological studies on polybutylene terephthalate," Journal of polymer science. Part A, vol. 18, no. 2, pp. 327-342, 1980.

[9] G. A. Olah, I. Bucsi, D. S. Ha, R. Aniszfeld, C. S. Lee, and G. K. S. Prakash, "Friedel-crafts reactions of buckminsterfullerene," Fullerene Science and Technology, vol. 5, no. 2, pp. 389-405, 1997.

[10] S. D Nabi and J. P. Jog, "Crystallization and equilibrium melting behavior of PBT/PETG blends," Journal of Polymer Science Part B, vol. 37, pp. 2439-2444, 1999.

[11] J. T. Yeh and J. Runt, "Multiple melting in annealed poly(butylene terephthalate)," Journal of Polymer Science, Part $B$, vol. 27, no. 7, pp. 1543-1550, 1989.

[12] M. Yasuniwa, T. Murakami, and M. Ushio, "Stepwise annealing of poly(butylene terephthalate)," Journal of Polymer Science, Part B, vol. 37, no. 17, pp. 2420-2429, 1999.

[13] C. W. Shyang, "Tensile and thermal properties of poly(butylene terephtalate)/organo-montmorillonite nanocomposites," Malaysian Polymer Journal, vol. 3, pp. 1-13, 2008.

[14] A. Woźniak-Braszak, J. Jurga, K. Jurga, B. Brycki, and K. Hołderna-Natkaniec, "Investigation of molecular reorientation in poly(butylene terephthalate)/decylamine/fullerene nanocomposites," Journal of Non-Crystalline Solids, vol. 356, no. 11-17, pp. 647-651, 2010.

[15] J. Vendramini, C. Bas, G. Merle, P. Boissonnat, and N. D. Alberola, "Commingled poly(butylene terephthalate)/unidirectional glass fiber composites: influence of the process conditions on the microstructure of poly(butylene terephthalate)," Polymer Composites, vol. 21, no. 5, pp. 724$733,2000$.

[16] V. L. Shingankuli, J. P. Jog, and V. M. Nadkarni, “Thermal and crystallization behavior of engineering polyblends. I. glass reinforced polyphenylene sulfide with polyethylene terephthalate," Journal of Applied Polymer Science, vol. 36, no. 2, pp. 335351, 1988.

[17] A. Bansal, H. Yang, C. Li, B. C. Benicewicz, S. K. Kumar, and L. S. Schadler, "Controlling the thermomechanical properties of polymer nanocomposites by tailoring the polymer-particle interface," Journal of Polymer Science, Part B, vol. 44, no. 20, pp. 2944-2950, 2006.

[18] C. F. Ou, M. S. Chao, and S. L. Huang, "Crystallization behaviors of poly(butylene terephthalate) blended with co[poly(butylene terephthalate-p-oxybenzoate)] copolyesters," European Polymer Journal, vol. 36, no. 12, pp. 2665-2670, 2000. 
[19] G. Broza, M. Kwiatkowska, Z. Rosłaniec, and K. Schulte, "Processing and assessment of poly(butylene terephthalate) nanocomposites reinforced with oxidized single wall carbon nanotubes," Polymer, vol. 46, no. 16, pp. 5860-5867, 2005.

[20] S. Z. D Cheng, R Pan, and B. Wunderlich, "Thermal analysis of poly(butylene terephthalate) for heat capacity, rigidamorphous content, and transition behavior," Die Makromolekulare Chemie, vol. 189, no. 10, pp. 2443-2446, 1988.

[21] A. Woźniak-Braszak, K. Jurga, J. Jurga, B. Brycki, and K. Hołderna-Natkaniec, "Solid state 1H NMR study of molecular dynamics and domain sizes in PBT with the fullerene derivates: decylamine- $\mathrm{C}_{60}$ and tetracyanoethylene oxide- $\mathrm{C}_{60}$," Journal of Non-Crystalline Solids, vol. 357, no. 3, pp. 11641171, 2011. 

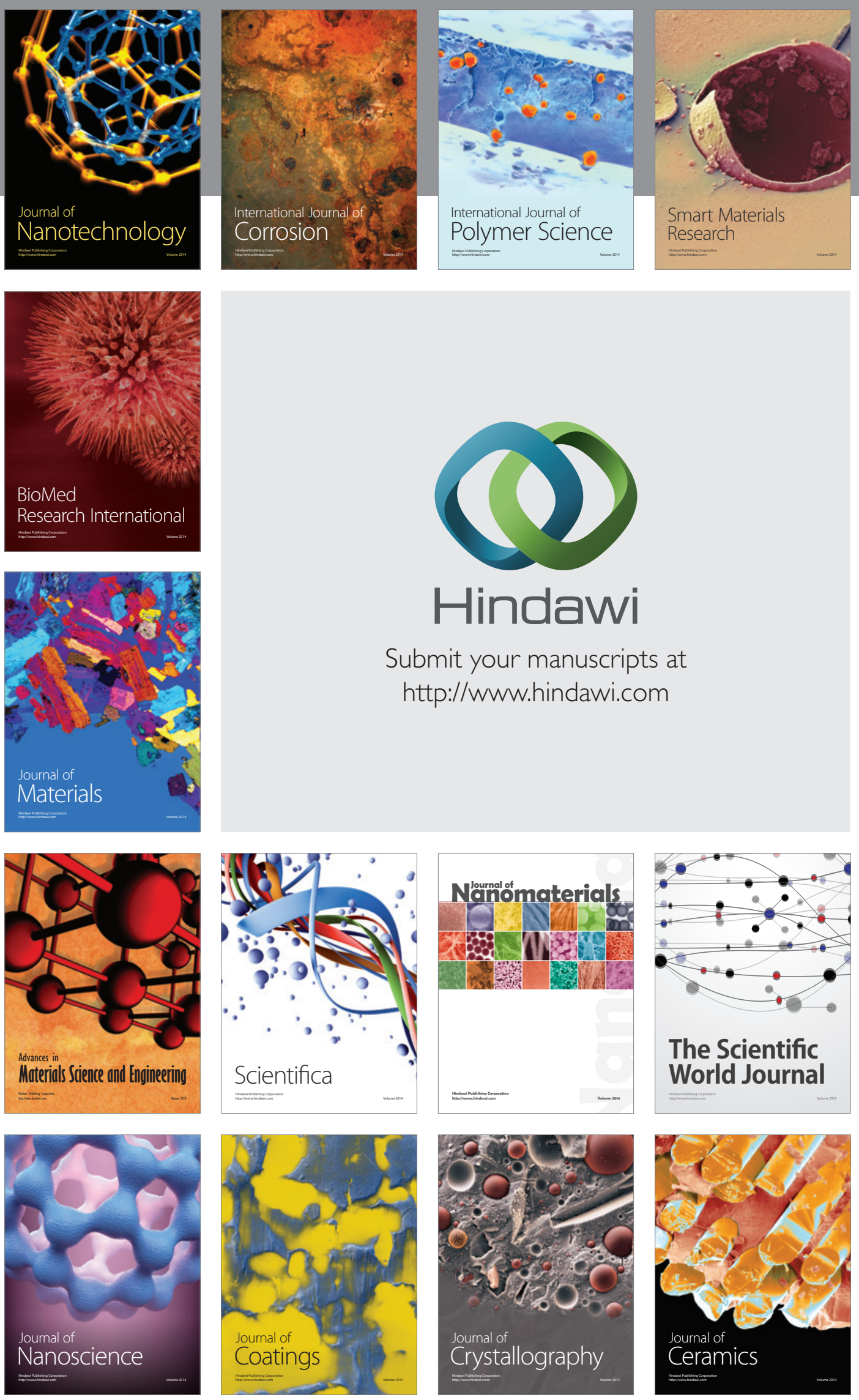

The Scientific World Journal

Submit your manuscripts at

http://www.hindawi.com

\section{World Journal}

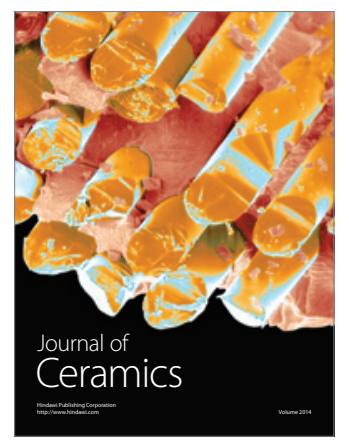

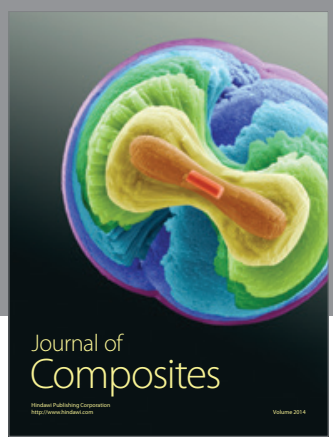
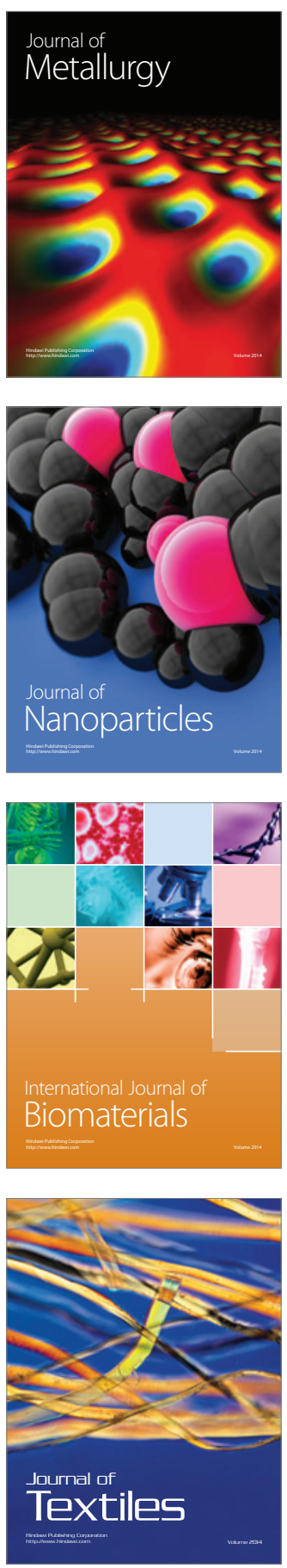